Altai State University

WWW.asu.ru

\title{
Biodiversity of silica-scaled chrysophytes in tributaries of northern limit of Lake Baikal
}

\author{
A.Yu. Bessudova, A.D. Firsova, I.V. Tomberg, L.M. Sorokovikova, Ye.V. Likhoshway \\ Limnological Institute of the Siberian Branch of the Russian Academy of Sciences, Irkutsk \\ annabessudova@mail.ru; firsova@lin.irk.ru; kaktus@lin.irk.ru; lara@lin.irk.ru; likhoshway@mail.ru
}

\begin{abstract}
Complex algological and hydrochemical studies were performed in July 2017 at the mouths of Upper Angara and Kichera rivers, as well as three mouths of Angara-Kichera estuary - Dushkachanskoye, Srednee and Dagarskoye, which supply water to Lake Baikal. The species diversity of scaled chrysophytes was studied via scanning and transmission electron microscopy. A total of 31 species and intraspecific taxa were detected: Chrysosphaerella - 1; Paraphysomonas 2; Spiniferomonas - 8; Mallomonas - 14; Synura - 6. As a result, the list of scaled chrysophyte species in the Baikal region was extended by 3 taxa and currently includes 76 species and intraspecific taxa, thus making its diversity of scaled chrysophytes the highest in the world.
\end{abstract}

Key words: hydrochemistry, silica-scaled chrysophytes, Kichera River, Verchnaya Angara River, Angarskiy Sor Bay, Northern Baikal.

\section{Биоразнообразие чешуйчатых хризофитовых в притоках северной оконечности озера Байкал}

\author{
A.Yu. Bessudova, A.D. Firsova, I.V. Tomberg, L.M. Sorokovikova, Ye.V. Likhoshway \\ Лимнологический институт Сибирского отделения Российской академии наук, Иркутск, Россия \\ annabessudova@mail.ru*; firsova@lin.irk.ru; kaktus@lin.irk.ru; lara@lin.irk.ru; likhoshway@mail.ru
}

\footnotetext{
В устьях рр. Верхняя Ангара и Кичера, а также в трех устьях Ангаро-Кичерской дельты, по которым осуществляется поступление вод в оз. Байкал, - Душкачанском, Среднем и Дагарском в июле 2017 г. проведены комплексные альгологические и гидрохимические исследования. С помощью сканирующей и трансмиссионной электронной микроскопии определен видовой список чешуйчатых хризофитовых, включающий 31 вид и внутривидовой таксон: Chrysosphaerella - 1; Paraphysomonas - 2; Spiniferomonas - 8; Mallomonas - 14; Synura - 6. В результате проведенных исследований список видов чешуйчатых хризофитовых Байкальского региона дополнился 3 таксонами и включает теперь 76 видов и внутривидовых таксонов, что характеризует его как наиболее богатый видами чешуйчатых хризофитовых в мире.

Ключевые слова: гидрохимия, чешуйчатые хризофитовые; река Кичера, река Верхняя Ангара, Ангаро-Кичерская дельта, Северный Байкал.
} 


\section{Введение}

Озеро Байкал - древнейшее и глубочайшее озеро в мире, расположенное в поясе умеренного климата (Baikal. Atlas, 1995). Главные реки, впадающие в озеро, - Селенга, Верхняя Ангара и Баргузин - суммарно несут около 63,5 км³ речных вод в год (Votintsev, Glazunov, Tolmacheva, 1965; Sorokovikova et al., 2015) и играют важнейшую роль в гидрологическом и гидрохимическом режиме озера, влияя на распределение гидробионтов.

Ранее в Байкальском регионе, охватывающем расположенное на р. Ангара Богучанское водохранилище, оз. Байкал, дельту р. Селенги и устье р. Баргузин было обнаружено 73 вида и внутривидовых таксона чешуйчатых хризофитовых (Bessubova, Likhoshway, 2017; Bessudova et al., 2017; Bessudova et al., 2018). Подобное высокое биоразнообразие чешуйчатых хризофитовых в одной биогеографической области встречается крайне редко и до сих пор зарегистрировано только в трех точках мира: в водоемах Большеземельской и Воркутинской тундр - 75 видов и внутривидовых таксонов (Siver et al., 2005); в водоемах Финляндии - 73 (Hallfors, Hallfors, 1988); в водоемах региона Аквитания (Франция) - 58 (Němcová et al., 2012). Цель работы - провести анализ биоразнообразия чешуйчатых хризофитовых в северной оконечности оз. Байкал в районе рр. Верхняя Ангара и Кичера, а также в Душкачанском, Среднем и Дагарском устьях, отличающихся по гидрофизическим и гидрохимическим характеристикам от ранее исследованных станций Байкальского региона.

\section{Материалы и методы}

Материалом для данного исследования послужили 16 проб, отобранных в июле 2017 г. в районе рр. Верхняя Ангара и Кичера и трех устьях - Душкачанском, Среднем и Дагарском (рис. 1).

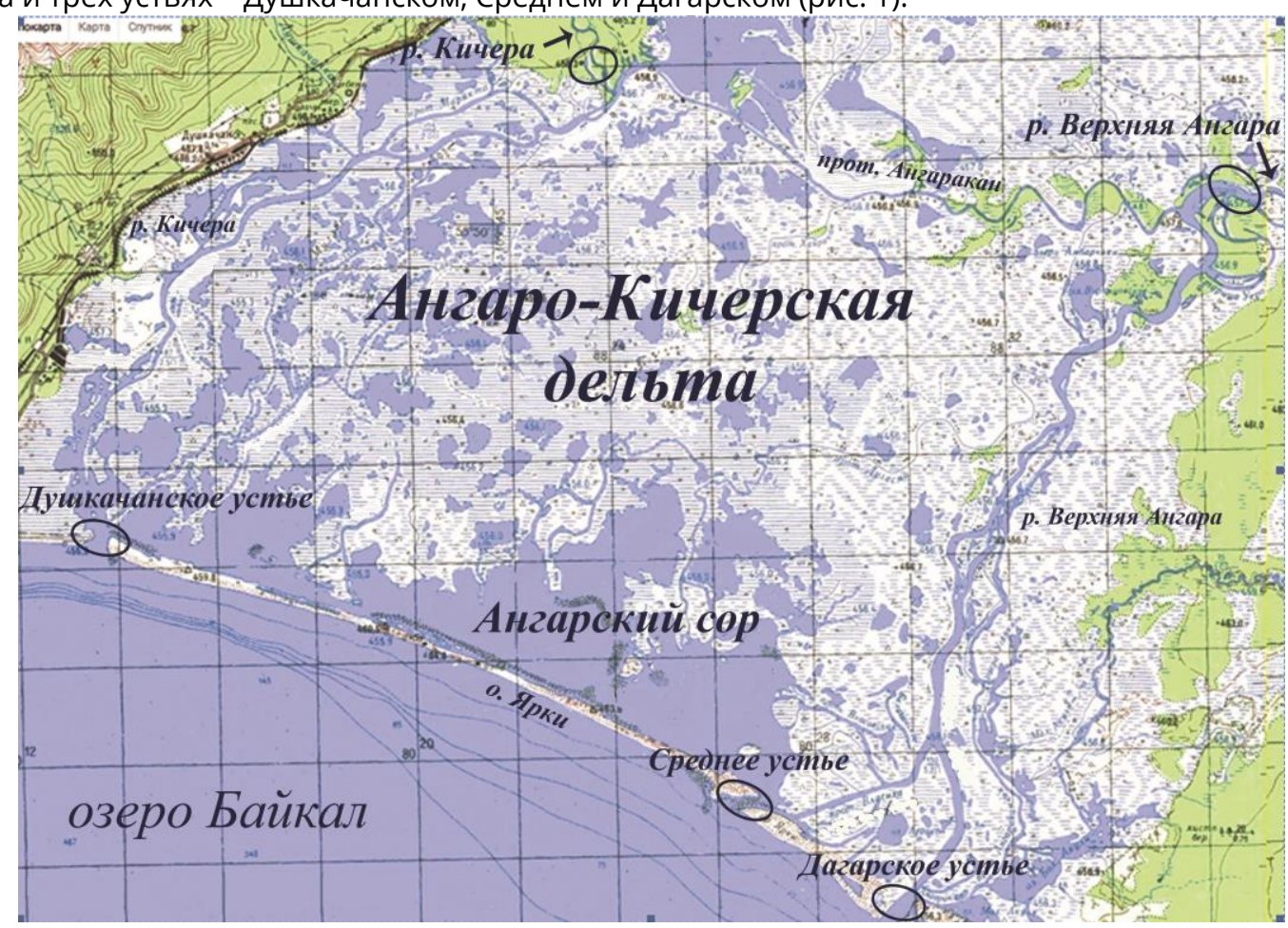

Рис. 1. Карта-схема отбора проб.

Отбор проб осуществляли батометром. Пробы на химический анализ фильтровали через мембранный фильтр с диаметром пор 0,45 мкм («Advantec», Japan). Определение биогенных элементов выполнено колориметрическими методами, общее содержание органического вещества определяли по бихроматной окисляемости (ХПК - химическое потребление кислорода) (Wetzel, Likens, 2003), анионы - методом высокоэффективной жидкостной хроматографии (Baram, Vereshchagin, Golobokova, 1999), катионы атомноабсорбционным и пламенно-эмиссионным методами (Manual ..., 2009). Достоверность полученных результатов проверялась регулярным проведением контроля качества анализов в рамках международной программы ЕANET по тестированию стандартных образцов поверхностных вод.

Альгологические пробы фиксировали йодным раствором Люголя, обработку проб проводили седиментационным методом (Kuzmin, 1975). Для более точного определения хризофитовых и их чешуек одновременно с батометрическими пробами осуществляли отбор образцов объемом 10-15 мл на фильтры с диаметром пор 1 мкм («Whatman», США), высушивали при комнатной температуре, напыляли золотом и исследовали с помощью сканирующего электронного микроскопа (СЭM) Quanta 200 («FEI Company», CША). Для трансмиссионной электронной микроскопии (ТЭМ) батометрические пробы осаждали, центрифугировали (MiniSpin, «Eppendorf», Германия) и отмывали дистиллированной водой, затем отмытую пробу прожигали 30 \% 
Bessudova, A.Yu. et al. Biodiversity of silica-scaled chrysophytes.... Acta Biologica Sibirica, 2018, 4(3), 75-84

$\mathrm{H}_{2} \mathrm{O}_{2}$ при $75^{\circ} \mathrm{C} 2$ ч, далее повторяли процедуру по отмыванию осадка. На сеточки диаметром 3 мм с формваровой пленкой-подложкой наносили отмытую пробу, высушивали при комнатной температуре и анализировали с помощью TЭM LEO 906E («Carl Zeiss», Германия).

Обилие хризофитовых оценивали по количеству чешуек, обнаруженных на фильтре в СЭМ в поле зрения при увеличении × 1000: 1 - «очень редко», от 1 до 3 чешуек; 2 - «редко», от 4 до 20 чешуек; 3 - «часто», от 21 до 65 чешуек (2-3 клетки); 4 - «обильно», более 66 чешуек (более 3 клеток).

\section{Район исследования}

Верхняя Ангара - второй (после р. Селенги) по водности приток, впадает в восточную часть северной оконечности озера (рис. 1). Среднегодовой сток реки составляет около 8,66 км³/год. Изменение климата с начала 90-ых гг. и повышение температуры воздуха способствовало таянию льда в деградирующих многолетнемерзлых породах и увеличению водного стока реки до 9,44 км³/год (Sorokovikova et al., 2015). Водный сток р. Кичера оценивался до 2,3 км³/год (Bogdanov, 1978). В верховьях характер рек горный, в нижнем течении они образуют общую Ангаро-Кичерскую дельту, изобилующую множеством мелких озер, часто сообщающихся друг с другом небольшими протоками, связывающими в одно целое ее западную и восточную части, а также залив Ангарский сор. Отделяет дельту и сор от Байкала узкий песчаный о. Ярки. Поступление вод из этой дельты в Байкал осуществляется по трем основным устьям (прорвам): Душкачанское русло, расположено в западной части дельты, Среднее и Дагарское - в восточной ее части. Душкачанское устье является общим и для стока вод р. Кичеры (Votintsev, Glazunov, Tolmacheva, 1965). Гидрохимические исследования, выполненные в 1950-1970-ых гг. (Votintsev, Glazunov, Tolmacheva, 1965; Bogdanov, 1978), выявили особенности внутригодовой динамики главных ионов, биогенных элементов и органических веществ в реках, впадающих в северную оконечность озера. Вода рек была слабоминерализованная, сумма ионов изменялась в воде Верхней Ангары от 48 до 120 мг/л, в Кичере - от 38 до 96 мг/л (Bogdanov, 1978). Повышение водности в последние годы привело к снижению суммы ионов до 36-112 мг/л в Верхней Ангаре и до 28-41 мг/л - в Кичере (Sorokovikova et al., 2015). Состав речных вод остается стабильным, по относительному содержанию главных ионов вода соответствует гидрокарбонатному классу, группе кальция. Концентрации биогенных элементов в водах рр. Кичера и Верхняя Ангара низкие, что является следствием малой освоенности их бассейнов человеком. По содержанию биогенных элементов воды этих двух рек соответствуют разрядам «очень чистая» и «вполне чистая». Общее содержание органических веществ по ХПК в воде обоих рек близкое и изменяется в пределах 3,6-19,0 мг/л, максимальные величины регистрируются во время половодья и летних паводков (Sorokovikova et al., 2015).

\section{Результаты и обсуждение}

\section{Сравнительный анализ гидрохимических параметров}

В период исследования температура воды в рр. Верхняя Ангара и Кичера составляли 15,7 и 19,4 ${ }^{\circ} \mathrm{C}$ соответственно. При прохождении по дельте температура воды повышается в Среднем и Дагарском устьях на 0,1$0,2{ }^{\circ} \mathrm{C}$, в Душкачанском на - на 2,0 ${ }^{\circ} \mathrm{C}$. Воды хорошо аэрированы, концентрация растворенного кислорода варьирует от 7,94 до 8,65 мг/ л (84-99 \% нас.). Величина рН воды в р. Верхняя Ангара, Среднем и Дагарском устьях составляет 7,56, в р. Кичере - 7,82, а в Душкачанском устье - 8,71. Минерализация воды низкая, сумма ионов в р. Верхняя Ангара составляет 47 мг/л, в р. Кичера - 40 мг/л. При прохождении по дельте сумма ионов в Душкачанском устье в сравнении с р. Кичера увеличивается на 10 мг/л, что может быть связано с поступлением более минерализованных вод притоков или подтоком подземных вод в пределах дельты. В р. Верхняя Ангара, Среднем и Дагарском устьях сумма ионов низкая, 44-46 мг/л. Концентрации биогенных элементов в воде исследованных водных объектов низкие (табл. 1). При прохождении по дельте в устьевых участках наблюдается снижение концентраций кремния, нитратного азота и фосфатного фосфора, что связано с повышением уровня развития фитопланктона при снижении скорости течения и увеличении температуры воды. Аналогичная картина наблюдалась при прохождении водных масс по дельте р. Селенги (Sorokovikova, Tomberg, Bashenkhaeva, 2008; Sorokovikova et al., 2009). Пространственная динамика концентраций аммонийного азота различается, в Среднем и Дагарском устьях его содержание увеличивается от входа в дельту к устью, тогда как в Душкачанском уменьшается, что зависит от особенностей формирования стока в пределах восточной и западной частях дельты и заболоченности территории. Необходимо отметить, что концентрации биогенных элементов в Дагарском и Среднем устьях различаются, хотя питание их определяется стоком р. Верхней Ангары (табл. 1). В воде Дагарского устья, куда поступает основной поток речных вод, концентрации биогенных элементов выше, чем в Среднем устье. Пониженное содержание кремния, азота и фосфора в Среднем устье определяется более интенсивным развитием водорослей при низкой водности и низких скоростях течения. Кроме того, здесь отмечено повышенное содержание аммонийного азота, что указывает на подток болотных вод. По содержанию биогенных элементов воды рр. Верхней Ангары и Кичеры в верхнем течении, а также в местах их поступления в Байкал, согласно классификации (Oksinuk et al., 1993), соответствуют разрядам «очень чистая» и «вполне чистая». По содержанию азота и фосфора воды р. Верхняя Ангара, р. Кичера и водотоках их дельты характеризуются как 
олиготрофные в отличие от р. Селенги и проток ее дельты, где значения этих показателей на порядок выше, что характерно для мезотрофных и эвтрофных водоемов (Sorokovikova et al., 2009). Содержание органических веществ по ХПК в воде рр. Кичера, Верхняя Ангара, а также в местах выхода речных вод в Байкал близки (табл. 1), в воде преобладает органическое вещество терригенного происхождения, отношение величины перманганатной окисляемости к бихроматной - более 40.

Таблица 1. Химический состав воды в рр. Верхняя Ангара, Кичера и их трех устьев в июле 2017 г. (мг/л)

\begin{tabular}{|c|c|c|c|c|c|c|}
\hline Места отбора проб & Si & $\mathrm{NH}_{4}^{+}$ & $\mathrm{NO}_{2}^{-}$ & $\mathrm{NO}_{3}^{-}$ & $\mathrm{PO}_{4}{ }^{3-}$ & $\mathrm{x} \boldsymbol{\mathrm { K }}$ \\
\hline р. Верхняя Ангара & 2,10 & 0,001 & 0,003 & 0,32 & 0,005 & 3,9 \\
\hline Дагарское устье & 1,96 & 0,006 & 0,004 & 0,25 & 0,003 & 4,5 \\
\hline Среднее устье & 1,42 & 0,009 & 0,003 & 0,22 & 0,003 & 4,4 \\
\hline р. Кичера & 1,70 & 0,018 & 0,001 & 0,17 & 0 & 5,6 \\
\hline Душкачанское устье & 1,54 & 0,005 & 0,001 & 0,14 & 0,001 & 5,1 \\
\hline
\end{tabular}

\section{Список видов и распределение чешуйчатых хризофитовых}

В результате микроскопического анализа проб, отобранных в районе исследований, всего обнаружен 31 вид и внутривидовой таксон чешуйчатых хризофитовых: Chrysosphaerella - 1; Paraphysomonas - 2; Spiniferomonas - 8; Mallomonas - 14; Synura - 6 (табл. 2; рис. 2, 3). Наиболее часто встречаются скопления клеток Mallomonas akrokomos, M. crassisquama, M. tonsurata, Spiniferomonas trioralis и Synura petersenii.

Таблица 2. Список видов и распределение чешуйчатых хризофитовых в районе исследований в июле 2017 г. Обилие оценивали по шкале (см. Материалы и методы)

\begin{tabular}{|c|c|c|c|c|c|c|}
\hline & Виды & р. Кичера & $\begin{array}{l}\text { р. Верхняя } \\
\text { Ангара }\end{array}$ & $\begin{array}{c}\text { Душкачанское } \\
\text { устье }\end{array}$ & $\begin{array}{l}\text { Среднее } \\
\text { устье }\end{array}$ & $\begin{array}{l}\text { Дагарское } \\
\text { устье }\end{array}$ \\
\hline 1. & $\begin{array}{l}\text { Chrysosphaerella } \\
\text { coronacircumspina Wujek \& } \\
\text { Kristiansen in: Wujek, Gretz, \& } \\
\text { Wujek }\end{array}$ & - & 1 & 2 & 2 & 2 \\
\hline 2. & $\begin{array}{l}\text { Spiniferomonas bourrellyi } \\
\text { Takahashi }\end{array}$ & - & 2 & 3 & 3 & - \\
\hline 3. & S. cornuta Balonov & 2 & - & - & 3 & - \\
\hline 4. & S. serrata Nicholls & - & 2 & 2 & 2 & - \\
\hline 5. & S. silverensis Nicholls & - & - & - & 2 & - \\
\hline 6. & S. triangularis Siver & 1 & 2 & - & - & - \\
\hline 7. & S. trioralis Takahashi & 2 & 2 & 3 & 3 & 3 \\
\hline 8. & S. trioralis f. cuspidata Balonov & - & 2 & - & 3 & - \\
\hline 9. & S. sp. & - & - & - & 1 & - \\
\hline 10. & $\begin{array}{l}\text { Paraphysomonas acuminata } \\
\text { acuminata Scoble et Cavalier- } \\
\text { Smith }\end{array}$ & - & - & - & 2 & - \\
\hline 11. & P. sp. & - & - & 1 & 2 & - \\
\hline & Mallomonas acaroides Perty & - & 1 & 2 & 3 & 2 \\
\hline & $\begin{array}{l}\text { M. akrokomos Ruttner in } \\
\text { Pascher }\end{array}$ & 1 & 2 & - & 3 & 2 \\
\hline & $\begin{array}{l}\text { M. alpina Pascher \& Ruttner in } \\
\text { Pascher }\end{array}$ & - & - & 1 & 3 & 3 \\
\hline & M. caudata Iwanoff & - & - & 2 & - & 2 \\
\hline 16. & M. corymbosa Asmund & - & - & 2 & 1 & 1 \\
\hline & M. costata Dürrschmidt & - & - & 2 & 1 & - \\
\hline & M. crassisquama Fott & - & 2 & 2 & 3 & 3 \\
\hline & $\begin{array}{l}\text { M. crassisquama var. papillosa } \\
\text { Siver \& Skogstad }\end{array}$ & - & - & - & 1 & - \\
\hline 20. & M. cratis Harris \& Bradley & - & - & - & - & 2 \\
\hline
\end{tabular}


Bessudova, A.Yu. et al. Biodiversity of silica-scaled chrysophytes.... Acta Biologica Sibirica, 2018, 4(3), 75-84

21. M. insignis Penard

22. M. cf. mangofera Harris \& Bradley

23. M. punctifera Korshikov

24. M. striata Asmund

25. M. tonsurata Teiling

26. Synura asmundiae (Cronberg \& Kristiansen) Škaloud, Kristiansen \& Škaloudová

27. S. glabra Korshikov

28. S. macropora Skaloud, Skaloudová, Procházková \& Nemcová

29. S. mammillosa Takahashi

30. S. petersenii Korshikov

31. S. spinosa Korshikov Всего

\begin{tabular}{lllll}
- & - & - & 1 & - \\
1 & - & - & 2 & - \\
- & - & - & 1 & 1 \\
- & - & 1 & 1 & 1 \\
2 & 3 & 3 & 3 & 3 \\
- & - & - & 1 & - \\
& - & - & & - \\
- & - & - & 2 & - \\
1 & 1 & - & - & - \\
& 2 & - & - & 3 \\
- & - & 2 & 3 & - \\
- & 12 & 15 & 26 & 13 \\
\hline 7 & & - & & \\
\hline
\end{tabular}

\section{Биогеографическое распределение редких видов чешуйчатых хризофитовых}

Настоящее исследование позволило выявить в районе р. Верхняя Ангара 12 видов и внутривидовых таксонов чешуйчатых хризофитовых, а в районе р. Кичера - 7 видов. Клетки обнаруженных видов чешуйчатых хризофитовых встречаются редко (табл. 2), образуя низкую численность. В Дагарском и Душкачанском устьях разнообразие чешуйчатых хризофитовых сопоставимо с речным участком Верхней Ангары, 13 и 15 видов и внутривидовых таксонов соответственно, однако клетки хризофитовых в устьях Ангаро-Кичерской дельты встречаются обильней. Наиболее разнообразно и обильно чешуйчатые хризофитовые представлены в Среднем устье. Среди обнаруженных здесь 26 видов 7 не встречаются в остальных исследованных в настоящей работе районах, что вероятно, связано с обогащением вод Среднего устья болотными водами. Низкие скорости течения, мелководность и более длительный период сезонного прогрева воды в этих трех устьях могут также способствовать более интенсивному развитию чешуйчатых хризофитовых, чем на речном участке (табл. 2).

Ранее в протоках дельты р. Селенги, отличающихся разнообразием условий формирования, мелководностью и высокими концентрациями биогенных элементов, было обнаружено 52 вида и внутривидовых таксона чешуйчатых хризофитовых (Bessudova et al., 2018), а в устье р. Баргузин - 35 (Bessudova et al., 2018). Несмотря на не самое высокое разнообразие чешуйчатых хризофитовых, определённое в настоящем исследовании (31), список видов чешуйчатых хризофитовых Байкальского региона дополнился тремя таксонами: редким видом - Synura mammillosa, обнаруженным впервые на территории России, Spiniferomonas sp. и Paraphysomonas sp., морфологически отличающихся от известных видов этих родов.

В районе исследования обнаружены редкие таксоны, это: Spiniferomonas silverensis, S. triangularis, Paraphysomonas acuminata acuminata, Mallomonas crassisquama var. papillosa, Synura asmundiae и S. macropora.

Spiniferomonas silverensis в водоемах России ранее был обнаружен в Харбейских озерах (Siver et al., 2005) и в Богучанском водохранилище (Bessubova, Likhoshway, 2017).

Spiniferomonas triangularis ранее на территории России был обнаружен в Воркутинской тундре (Siver et al., 2005), в небольшом термокарстовом озере бассейна Нижнего Енисея (Bessubova et al., 2016; Bessubova et al., 2018) и в Богучанском водохранилище (Bessubova, Likhoshway, 2017).

Paraphysomonas acuminata acuminata в водоемах России ранее был отмечен только в Байкальском регионе - в устье р. Баргузин, протоках дельты р. Селенги (Bessudova et al., 2018) и оз. Байкал (Bessudova et al., 2017).

Редкая разновидность Mallomonas crassisquama var. papillosa обнаружена ранее в Воркутинской тундре (Siver et al., 2005), в оз. Лабынкыр и Ворота (Республика Саха, Якутия) (Bessudova et al., 2016), в бассейне Нижнего Енисея (Bessubova et al., 2016; Bessubova et al., 2018), оз. Фролиха, расположенном на северо-востоке от оз. Байкал (Gusev, 2016), и оз. Санхар (Gusev, 2013).

Synura asmundiae обнаружена в России только в устье р. Баргузин (Bessudova et al., 2018).

S. macropora отмечена ранее в окрестностях пос. Борок (Gusev et al., 2016) и в Рыбинском водохранилище (Balonov, 1976). 

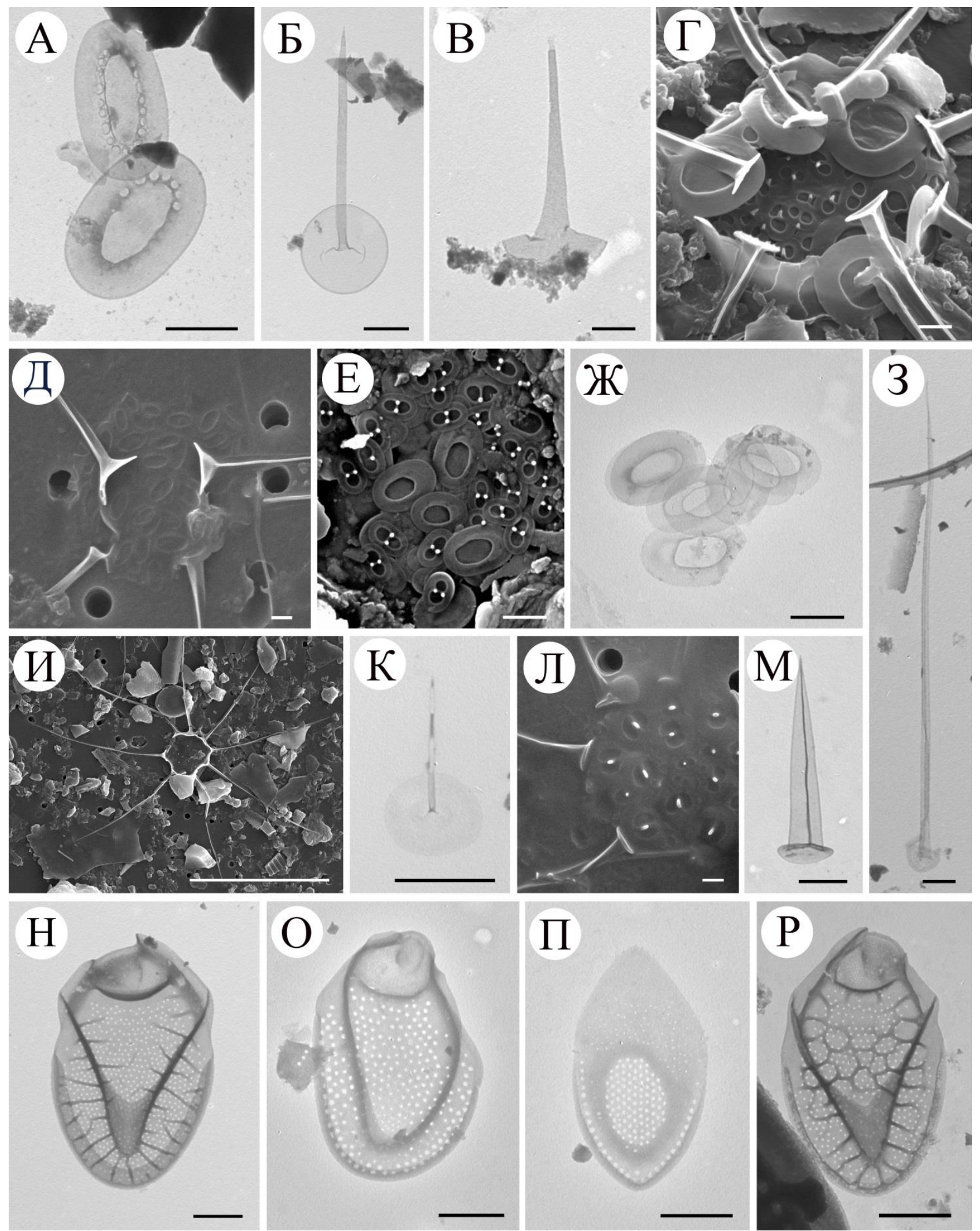

Рис. 2. СЭМ (Г-Е, И, Л), ТЭМ (А-В, Ж, З, К, М-Р). Чешуйки и шипы хризофитовых видов нескольких родов в районе исследований: A - Chrysosphaerella coronacircumspina (Среднее устье); Б - Paraphysomonas sp. (Душкачанское устье); В - Spiniferomonas bourrellyi (р. Верхняя Ангара); Г - S. serrata (Среднее устье); Д - S. silverensis (Среднее устье); E - S. cornuta (Среднее устье); ж, M -S. trioralis (р. Верхняя Ангара); 3 - S. trioralis f. cuspidata (р. Верхняя Ангара); И - S. sp. (Среднее устье); K - Paraphysomonas acuminata acuminata (Среднее устье); Л - S. triangularis (р. Верхняя Ангара); H - Mallomonas acaroides (Душкачанское устье); О - M. alpina (Душкачанское устье); $\Pi$ - M. akrokomos (Дагарское устье); Р - М. crassisquama (Среднее устье). Масштаб: А-З, К-Р - 1 мкм; И - 20 мкм 

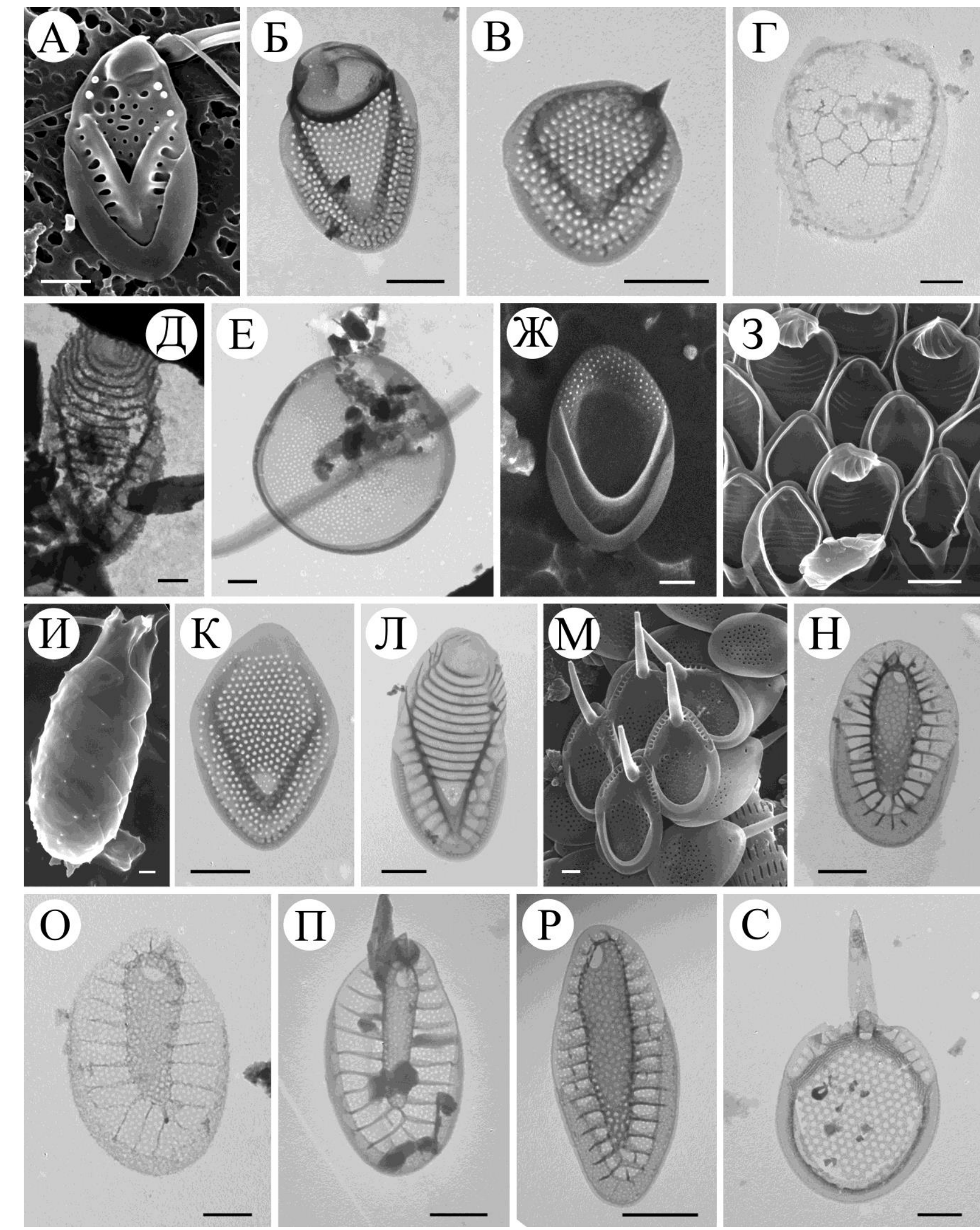

Рис. 3. СЭМ (А, Ж-И, М), ТЭМ (Б-Е, К, Л, Н-С). Чешуйки хризофитовых родов Mallomonas и Synura в районе исследований: А - Mallomonas crassisquama var. papillosa (Среднее устье); Б, В - М. corymbosa (Душкачанское устье); Г - M. punctifera (Среднее устье); Д - M. cratis (Дагарское устье); Е - M. caudata (Дагарское устье); Ж - M. insignis (Среднее устье); 3 - M. costata (Душкачанское устье); И - M. cf. mangofera (Среднее устье); К - M. tonsurata (Среднее устье); Л - M. striata (Дагарское устье); M - Synura spinosa (Среднее устье); H - S. asmundiae (Среднее устье); O - S. macropora (р. Кичера); П - S. glabra (Среднее устье); P - S. petersenii (Среднее устье); C - S. mammillosa (р. Верхняя Ангара). Масштаб: 1 мкм 


\section{Особенности морфологии некоторых чешуйчатых хризофитовых}

Обнаружены клетки, чешуйки и шипы которых морфологически сходны с видом Spiniferomonas silverensis, но отличаются от типа рядом признаков. Так, клетки обнаруженных экземпляров Spiniferomonas sp. имеют 8 трехгранных шипов 14-19 мкм длинной конусовидно суженных и бифуркатных у вершин. Базальный диск имеет от 1,5 до 2,5 мкм в диаметре. В отличие от вида Spiniferomonas silverensis, имеющего в составе клетки один тип чешуек - эллипсоидные с одной овальной лакуной и широкой каймой, у Spiniferomonas sp. встречаются два вида чешуек. Первый тип - чешуйки простые, эллипсоидные с одной овальной лакуной и широкой каймой. Второй тип - эллипсоидные с одной овальной лакуной и выростом на кайме лакуны, расположенном на 2/3 длины чешуйки. Высота выростов достигает 0,3 мкм (рис. 4).

Строение чешуек Spiniferomonas sp. сходно с чешуйками S. trioralis. Однако главной отличительной особенностью чешуек Spiniferomonas sp. от других чешуек рода Spiniferomonas, имеющих выросты, является их расположение на чешуйке. Выросты располагаются не на мостике, не по одну или обе стороны от него, как почти у всех видов с выростами, а на кайме лакуны. Этот признак объединяет его с видом Spiniferomonas breaknecki Siver.
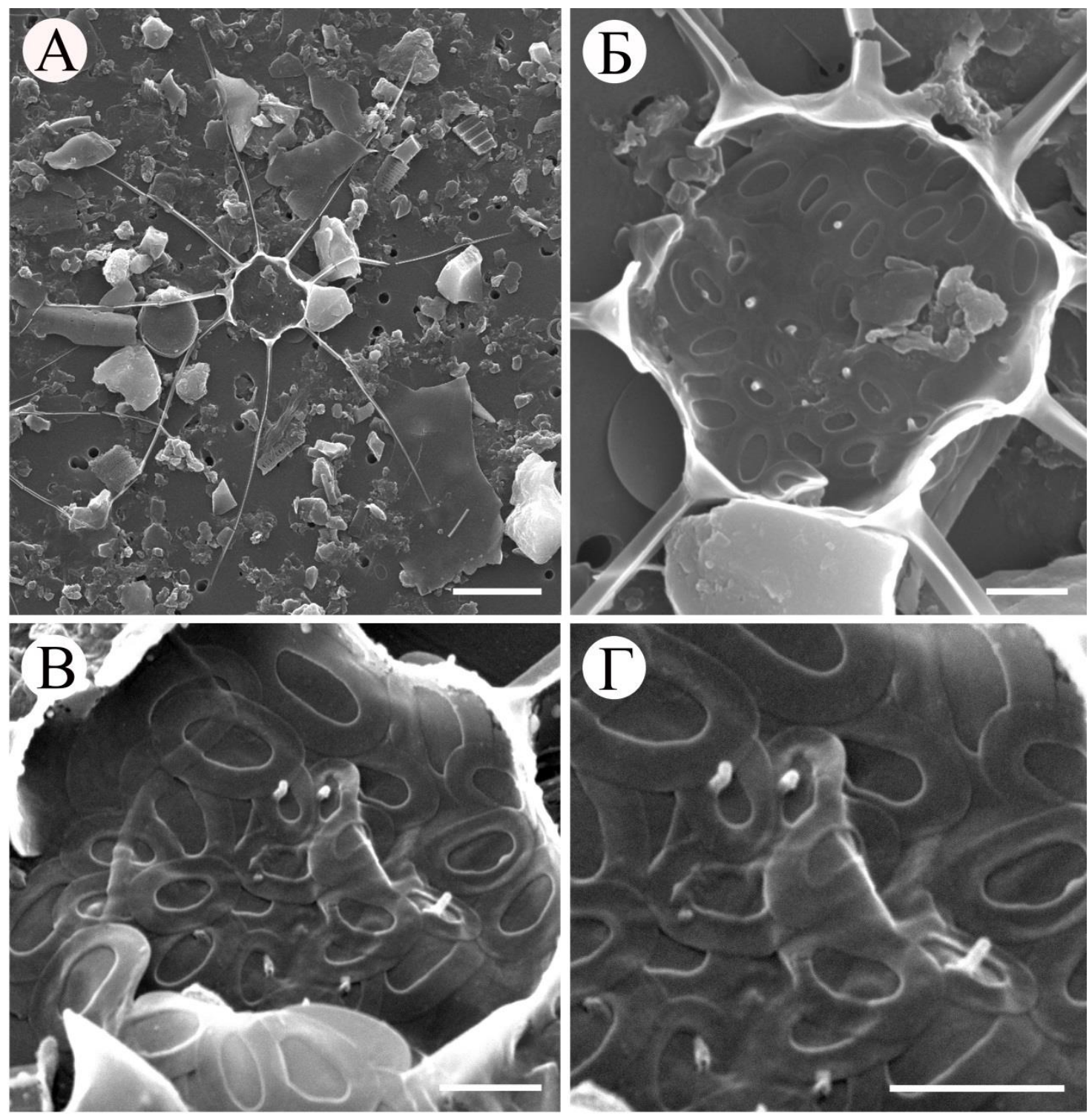

Рис. 4. СЭМ. Spiniferomonas sp. из вод Среднего устья: А - распавшаяся клетка с длинными шипами; Б основания шипов и чешуйки двух типов; В, Г - чешуйки двух типов: эллипсоидные чешуйки с одной овальной лакуной и широкой каймой и эллипсоидные с одной овальной лакуной и выростом на кайме лакуны. сэм. Масштаб: А - 10 мкм; Б-Г - 1 мкм

Обнаруженные отдельные шипы Paraphysomonas sp. на основании описанных ранее деталей тонкой структуры (Scoble, Cavalier-Smith, 2014) определить до вида не удалось. Обнаруженные шипы имеют округлую форму основания пластинки 1,8-2,2 мкм в диаметре и выраженный ободок кромки пластинки. Шип 5,2-5,5 мкм длиной, у основания немного тоньше, чем в середине шипа. Вершина шипа заострена (рис. 2 Б). 
Bessudova, A.Yu. et al. Biodiversity of silica-scaled chrysophytes... Acta Biologica Sibirica, 2018, 4(3), 75-84

Клетки, отмеченные нами как Mallomonas cf. mangofera, попадались в плотной слизистой оболочке, что не позволило достоверно определить их до вида, однако, по едва заметному морфологическому строению чешуек и форме клетки можно предположить, что это вид Mallomonas cf. mangofera.

Таким образом, список видов чешуйчатых хризофитовых Байкальского региона дополнился видами Sуnura mammillosa, Spiniferomonas sp. и Paraphysomonas sp. и насчитывает теперь 76 видов и внутривидовых таксонов, что позволяет охарактеризовать этот регион как однин из наиболее богатых видами чешуйчатых хризофитовых районов в мире. Наибольшего обилия и разнообразия чешуйчатые хризофитовые в Байкальском регионе достигают в мелководных и хорошо прогреваемых водах, вопреки существующему ранее мнению о приуроченности их к холодноводным олиготрофным условиям обитания (Matvienko, 1954; Starmach, 1985).

\section{Благодарности}

Отбор проб и гидрохимический анализ выполнен в рамках бюджетной темы № 0345-2016-0008, исследование видового состава чешуйчатых хризофитовых выполнено при финансовой поддержке РФФИ в рамках проекта № 1834-00203, электронная микроскопия - в рамках бюджетной темы № 0345-2016-0001 в ПЦ «Электронная микроскопия», входящем в ЦКП «Ультрамикроанализ» Лимнологического института СО РАН.

\section{References}

Atlas and Key of Baikal Pelagic bionts (with brief profiles of their ecology) (1995). In: Timoshkin, O.A., Mazepova, G.F., Melnik, N.G. et al. (Eds). Novosibirsk: Nauka (in Russian).

Balonov, I.M. (1976). Biology, morphology and taxonomy of aquatic organisms. Proceeding of IBIW AS USSR, 31(34), 174 (in Russian).

Baram, G.I., Vereshchagin, A.L., Golobokova, L.P. (1999). Application of Microcolumn HPLC with UV Detection to Analysis of Anions in Environmental Objects. Zhurnal Analiticheskoi Khimii, 54, 962-965 (in Russian).

Bessudova, A.Yu., Firsova, A.D., Sorokovikova, L.M., Tomberg, I.V. (2016). Silica-scaled chrysophytes of the Lower Yenisei basin and bays of the Kara Sea with autecology elements. Irkutsk: Institute of Geografy (in Russian).

Bessudova, A., Tomberg, V., Firsova, A.D., Kopyrina, L.I., Likhoshway, Ye.V. (2016). Silica-scaled chrysophytes in lakes Labynkyr and Vorota, Yakutia, Russia. $9^{\text {th }}$ International Chrysophyte Symposium (ICS9), Japan, Yamagata.

Bessubova, A.Yu., Likhoshway, Ye.V. (2017). Silica chrysophytes (Chrysophyceae) of the Boguchany reservoir. Modern science: actual problems of theory and practice. Series "Natural and technical sciences (General biology), 11, 4-11 (in Russian). URL: http://www.nauteh-journal.ru/index.php/----etn17-11/3936-a

Bessudova, A.Yu., Domysheva, V.M., Firsova, A.D., Likhoshway, Y.V. (2017). Silica-scaled chrysophytes of Lake Baikal. Acta Biologica Sibirica, 3(3), 47-56. DOI: http://dx.doi.org/10.14258/abs.v3i3.3615

Bessudova, A.Yu., Sorokovikova, L.M., Tomberg, I.V., Likhoshway, E.V. (2018). Silica-scaled chrysophytes in large tributaries of Lake Baikal. Cryptogamie, Algologie, 39(2), 145-165. DOI:10.7872/crya/v39.iss2.2018.145

Bessudova, A., Bukin, Y.S., Sorokovikova, L.M., Firsova, A.D., Tomberg, I.V. (2018). Silica-scaled chrysophytes in small lakes of the lower Yenisei basin, the arctic. Nova Hedwigia. DOI: https://doi.org/10.1127/nova_hedwigia/2018/0473

Bogdanov, V.T. (1978). Formation of the hydrochemical regime of the Northern Baikal. Novosibirsk: Nauka (in Russian).

Hällfors, G., Hällfors, S. (1988). Records of chrysophytes with siliceous scales (Mallomonadaceae and Paraphysomonadaceae) from Finnish inland waters. Flagellates in freshwater ecosystems. Hydrobiologia, 161, 1-29. DOI: 10.1007/978-94-009-3097-1_1

Gusev, E.S. (2016). Contribution to the flora of silica-scaled chrysophytes of Frolikha Lake (North transbaikal area). Proceeding of IBIW RAS, 76 (79): 25-30 (in Russian).

Gusev, E.S. (2013). Silica-scaled chrysophytes from low-mineralized karst lakes in Central Russia. Nova Hedwigia, Beihefte, 142, 17-25.

Kuzmin, G.V. (1975). Phytoplankton. Species composition and abundance. Methods for studying biogenocenoses of inland waters. Moscow: Nauka (in Russian).

Matvienko, A.M. (1954). Zolotistye vodorosli. Opredelitel' presnovodnykh vodoroslei SSSR (Chrysophyte Algae: Identification Key to Freshwater Algae of the Soviet Union). Moscow: Sovetskaya Nauka, 188 p. (in Russian).

Němcová, Y., Kreidlová, J., Kosova, A., Neustupa, J. (2012). Lakes and pools of Aquitania region (France) - a biodiversity hotspot of Synurales in Europe. Nova Hedwigia, 95: 1-24. DOI: 10.1127/0029-5035/2012/0036

Manual for chemical analysis of inland surface waters. (2009). Part 1. Rostov-on-Don: NOK, 1045 p. (in Russian). Oksinuk, O.P., Zhukinsky, V.N., Braginsky, L.P., Linnik, P.N., Kuzmenko, M.I., Klenus, V.G. (1993). Integrated ecological classification of inland surface waters. Hydrobiological Journal, 4, 62-76 (in Russian).

Scoble, J.M., Cavalier-Smith, T. (2014). Scale evolution in Paraphysomonadida (Chrysophyceae): Sequence phylogeny and revised taxonomy of Paraphysomonas, new genus Clathromonas, and 25 new species. European Journal of Protistology, 50, 551-592. DOI: 10.1016/j.ejop.2014.08.001

Siver, P.A., Voloshko, L.N., Gavrilova, O.V., Getsen, M.V. (2005). The scaled chrysophyte flora of the Bolshezemelskaya tundra. Nova Hedwigia Beiheft, 128, 125-150. 
Sorokovikova, L.M., Tomberg, I.V., Bashenkhaeva, N.V. (2008). The chemical composition of Selenga river waters and its Delta / Delta of the Selenga River as a biofilterand indicator of the state of Lake Baikal. Novosibirsk: Nauka (in Russian).

Sorokovikova, L.M., Popovskaya, G.I., Tomberg, I.V., Bashenkhaeva, N.V. (2009). Spatial and temporal variability of nutrient and organic matter concentrations and phytoplankton in the water of the Selenga River and channels of its delta. Water resources, 36(4), 465-474 (in Russian).

Sorokovikova, L.M., Sinyukovich, V.N., Tomberg, I.V., Marinaite, I.I., Khodzher, T.V. (2015). Assessment of water quality of Lake Baikal tributaries from chemical parameters. Geography and natural resources, 36 (1), $37-45$ (in Russian).

Starmach, K. (1985). Chrysophyceae and Haptophyceae. Jena: Gustav Fischer, Verlag.

Votintsev, K.K., Glazunov, I.V., Tolmacheva, A.P. (1965). Hydrochemistry of rivers of Lake Baikal basin. Moscow: Nauka (in Russian).

Wetzel, R.G., Likens, G.E. (2003). Limnological Analyses. N.Y.: Springer-Verlag.

\section{Citation:}

Bessudova, A.Yu., Firsova, A.D., Tomberg, I.V., Sorokovikova, L.M., Likhoshway Ye.V. (2018). Biodiversity of silicascaled chrysophytes in tributaries of northern limit of Lake Baikal. Acta Biologica Sibirica, 4 (3), 75-84.

Submitted: 23.06.2018. Accepted: 05.08.2018

cross ref http://dx.doi.org/10.14258/abs.v4i3.4411

(C) 2018 by the authors. Submitted for possible open access publication under the terms and conditions of the Creative Commons Attribution (CC BY) license (http://creativecommons.org/licenses/by/4.0/). 